Butterfies and Moths (British). By W. FurNEAUX. London, Longmans. 1894. $12^{\circ}$. This is by no means a complete treatise on these insects, which would be quite impossible in the 350 pages to which it is limited; but rather a selection has been made of such as the author thinks would prove most desirable. The number of British butterflies, however, is so limited (66 species) that place is found for all of them. A brief description and general acconnt is given of each species mentioned, together with a figure of most of them; a certain amount of attention is paid to the early stages and especially to the caterpillar; but the book is very weak indeed on all points as to classification, the common characters of groups being hardly hinted at; it is therefore intended almost exclusively for the amateur, and not for the serious student. The introduction, which occupies about a third of the book, and is of as much interest to an outsider as to a Briton, is exceptionally good for a work of this class, though here again it is lean as regards all matters of structure or classification. The illustrations in the text, and they are numerous, are with few exceptions unusually good; those on the twelve colored plates not so good. The figure of the egg of Pieris brassica, on p. 14 , is upside down.

S. H. S.

The Pygmies. By A. DE Quartrefages. Translated by Frederick Starr. Illustrated. Pp. 255. D. Appleton \& Co. 1895.

This volume forms number 2 of the Anthropological Series, edited by Professor Starr, of the University of Chicago. The original appeared in Paris about eight years ago, and the name of the distinguished author, as well as the interest of the subject, insured it considerable attention.

He approaches the topic historically with a chapter on the accounts of the pygmies which are found in classical writings, and an attempt to analyze them in the light of modern research. Turning to later sources, a full history is supplied of what was known ten years ago of the dwarf tribes of Melanesia, of the Mincopies of the Andaman islands, of the Negritos of Indonesia, of the Negrillos of Central Africa, and of the Hottentots and Bushmen of the southern portions of that continent. Special attention is given to the physical peculiarities of the tribes mentioned and to their sociologic condition. A chapter of some length is devoted to the religious beliefs of the Bushmen and Hottentots, successfully controverting the statement often advanced that these humble peoples had no religion at all. The illustrations, thirty-one in number, are fairly well done, though printed rather carelessly. The translator has accomplished his task well, and the text reads pleasantly.

It is to be regretted that the large material accumulated in the last ten years on this subject was not more freely called upon. Mr. Haliburton, Professor Kollman and Dr. Virchow have contributed monographs which should not be overlooked. Emin Bey's anthropometric reports on the Negrillos are the best we have; but these names are not referred to. We should have liked, also, a chapter on the causes which bring about decrease in stature, a physiological study of its etiology. Probably any people would become dwarfs under given conditions, and the trait is therefore not a racial one. D. G. Brinton.

\section{An Introduction to Structural Botany (Flower-} ing Plants). By D. H. Scotт. London and New York, Macmillan \& Co. 288 pp. 113 figs. $\$ 1.00$.

The author intends that this shall be a book for beginners. Three types are chosen to illustrate the structure of the flowering plants, the wall flower (Cheiranthus Cheiri 